\title{
English as the Lingua Franca in Visual Touristic Jordan: The Case of Petra
}

\author{
Omar Ibrahim Salameh Alomoush ${ }^{1 *}$, Ghazi Khaleel Al-Na'imat ${ }^{2}$ \\ ${ }^{1}$ English Department, Tafila Technical University, P. O. Box 179, Tafila 66110, Jordan \\ ${ }^{2}$ English Department, Al-Hussein University, Jordan
}

Corresponding Author: Omar Ibrahim Salameh Alomoush, E-mail: alomoushomar@ttu.edu.jo

\begin{tabular}{l} 
ARTICLE INFO \\
\hline Article history \\
Received: January 11, 2018 \\
Accepted: March 15, 2018 \\
Published: July 01, 2018 \\
Volume: 7 Issue: 4 \\
Advance access: May 2018
\end{tabular}

Conflicts of interest: None Funding: None

\begin{abstract}
This article examines the linguistic landscape (LL henceforth) of a southern Jordanian town, Petra. It also attempts to display how English is used by both commercial shops and companies in the local tourist industry to construct and shape touristic visual Jordan. All linguistic signs were photographed by using a digital camera and coded according to function (e.g., government and commercial signage) and language (e.g., English, Arabic, French, Spanish, etc.). The current article has already taken into account ethnographic developments in LL methodology and directly involved with individuals from the foreign tourist population and local residents (e.g., shopkeepers, restaurant workers and owners, and so on) to identify how the English language has been negotiated and used as the lingua franca of the local and foreign tourist populations and a symbol of linguistic globalization in the LL of touristic Jordan. Although many languages have found a relatively long-lived niche in the LL of Jordanian cities in previous LL studies (Alomoush, 2015), the current study results indicate that the touristic public space is largely dominated and controlled by the English language in the sense that there is much higher vitality of English than other languages, including Arabic in the LL. This is closely associated with the reciprocal relationship between English and globalization, communicative and economic motivations, and the participants' positive attitudes toward English.
\end{abstract}

Key words: English, Lingua Franca, Globalization, Linguistic Diversity, Linguistic Landscape, Petra, Touristic Jordan

\section{INTRODUCTION}

Based on Kachru's (1986) 'concentric circles', many linguists, including but not limited to Bolton (2005, 2012), Yano (2001), and Rubdy \& Saraceni (2001) have started to assess the relative status of their own English. That is why the term 'new' Englishes has been utilized in both the 'Inner'(e.g., American and British English) and 'Outer' Circles (e.g., Pakistani English and Malaysian English), whilst Englishes in the 'Expanding' Circle (e.g., Jordanian English and Lebanese English) are no longer considered as separate new Englishes.

The spread of English throughout the globe has been examined from several theoretical perspectives. It has been suggested that there is a mutual relationship between English, colonialism, and capitalism (Phillipson, 1992, 2015, \& 2016; Pennycook, 2001 \& 2007). On the one hand, Pennycook (2001) does not accept the claim that the spread of the English language has been natural, unbiased, or advantageous, as suggested by Crystal (1997), refuting the assertion made by Fishman et al (1977) that the expansion of the English language is never ideologically driven. On the other hand, Phillipson's (1992) 'linguistic imperialism' empha- sizes that the proliferation of English is accompanied with that of the Anglo-American culture. In the current study, we believe that English has recently become an important contributor to the development of nations nationally and internationally, but it might be linked to forms of cultural homogenization and Western values. This does not mean that other languages cannot be a global medium of intercultural communication, social and economic advancement, but the current social, economic, and political circumstances have made English the best linguistic code in visual tourist destinations.

The Jordanian government promotion of inbound tourism as an important source of economic prosperity, with a target to increase the total number of tourists up to 9.4 million and domestic and non-domestic tourism receipts to JD 4.2 billion (Ministry of Tourism and Antiquities), the tourism industry provides a livelihood for many inhabitants of the country. As the tourism business is growing steadily in Jordan, Ministry of Tourism and Antiquities has been taking action to improve foreign language skills among staff and students. Perhaps it is hardly surprising that English is intensively and extensively used on public and commercial display signs, given the fact that it is a reflection of socio-political and economic 
advancement and development. The city of Petra's touristic appeal is, therefore, culturally enhanced through the employment of English signs everywhere in the city, particularly in the areas where tourists come across. Unsurprisingly then, the local people and foreign tourists often resort to English as a medium of wider communication when they do not have a language in common.

One of the most significant developments, especially after the dissolution of the USSR, which has a tremendous effect on our lives, is the process of globalization. It becomes apparent that the phenomenon itself is growingly associated with negative terms such as Americanization and McDonaldization that aim to homogenize other peoples and cultures (Pieterse, 2009).In the current era of globalization and internationalization, English has been useful and an essential part of the sociolinguistic mosaic of many states and regions, especially those which have colonial past (Stavans \& Hoffman, 2015). The historical perspective compels us to argue for the notion of power and inequality based on sociolinguistic considerations, which means that people may be politically, socially, and educationally stratified and categorized according to the language used (Blommaert, 2010).

In the case of Jordan, due to cultural globalization and the increasing popularity of the American and British culture, the spread of the English language has gone far beyond the educational social settings and domains. It is astonishing that English has been intruding into more domains whose access is typical of the varieties of Arabic, especially among members of affluent classes. In a similar manner to the prolific use of English in the literature as being described as a 'global', 'international' or 'world language' (e.g., Phillipson, 1992 \& 2009), modern media communication resources have made it possible for many Jordanians to use the lingua franca of the globe, namely English, on a regular basis. Economic factors also seem to be deciding factors in the increasing popularity of English among Jordanians, especially young generations.

\section{Linguistic Landscape And The Present Study}

LL studies have been conducted in most parts of the world, including but not limited to France and Italy (Blackwood \& Tufi, 2015), Japan (Backhaus, 2007), Jordan (Al-Naimat, 2015; Alomoush, 2015), and the Netherlands and the Basque Country (Cenoz \& Gorter, 2006). In their study of the LL, Scollon \& Scollon (2003:7) develop the term 'geosemiotics', 'the study of the social meaning of the material placement of signs in the world', as covering systems of both 'social positioning and power relationships at the level of interpersonal relationships and at the level of struggle for hegemony among social groups in any society'. The LL is, therefore, worth-studying as a mere reflection of cultural, socio-political, and economic changes that occur in a speech community. This in practice means that the LL provides a particularly valuable setting for the examination of the sociolinguistics of the languages used on signs.

LLs in touristic attractions and destinations are places of language conflicts, not only reflecting the tensions between languages displayed on signs, but also highlighting the growing linguistic intrusion of visual English in the domain of tourism, commerce, and even government-related institutions. Given the wealth of literature, we cannot mention and refer to all the studies that examined English in the developing and developed countries.

Based on what has already been pointed out, the LL is primarily a sign of linguistic diversity in both rural and urban areas. That is why it might be significantly employed by the state and commercial agencies as a space for the implementation of language policies. In this sense, the LL is a dynamic space that is most likely reconstructed and renegotiated in a very short period of time by historical, socio-political, and economic forces. According to Alomoush (2015), English appeared as the second most visually dominant language after Arabic; both Arabic and English engaged in a mode of linguistic competition in the visual marketplace of Jordanian cities.

The current study is of great relevance due to the consideration that it supports the value of LL research as a demonstration of power structures within a speech community, region, state (Gorter, 2006; Scollon \& Scollon, 2003). Indeed, the present study can tell us about how English is visually used in an Arab Middle Eastern country in commercial and touristic settings in that English as a lingua franca primarily addressing foreign tourists is significantly competing with the Arabic language. Unlike other languages, it is English, the lingua franca by virtue of socioeconomic power, that normally wins out. As a result of what has been already researched in the LL of Jordanian cities and drawing upon a corpus of 210 signs collected from Petra Central Street and the subsequent interviews and meetings with foreign tourists and shopkeepers, we seek to find answers to two main research questions:

1. What is special about English displays in touristic Jordan? 2. Are there any other languages competing with English?

Linguistic landscapers (Backhaus, 2007; Kallen, 2009; Reh, 2004) have suggested different models for the interpretation of linguistic signs in the LL. The theoretical backdrop to this LL study is the assertion that the reciprocal relationship between English and globalization gives rise to the high incidence of signs in English in Jordanian touristic towns, as will be displayed in the case study of Petra. Based on this analytical theoretical framework, English as an international language has resulted in a range of social, historical, and cultural constraints (Pennycook, $2001 \&$ 2006). This model aims to better understand the reasons behind monolingual and multilingual ideological practices which are constrained according to deliberate language decisions. It also deepens our understanding of the wide spread of English in new touristic LLs and why English has been visually rapidly infiltrating into touristic visual Jordan, displaying varying degrees of reactions to linguistic globalization and English.

This paper will not look at the degree of correctness of English, which has been highlighted by Blommaert (2010) who uses grassroots literacy in order to explain the new linguistic features of the use of English in a specific geographical area. Rather, it is intended to analyze the sociolinguistic circumstances and dimensions of the display of English in touristic Jordan in accordance with the perspectives of both foreign tourists and local residents. 


\section{Background Information and Jordan's Sociolinguistic Profile}

Jordan, a state in the Levantine region, shares its borders with Iraq, Saudi Arabia, Syria, and Palestine. The country's history and culture are influenced by Turkey, Britain, and recently the USA. Arabic is the official language of the state of Jordan.

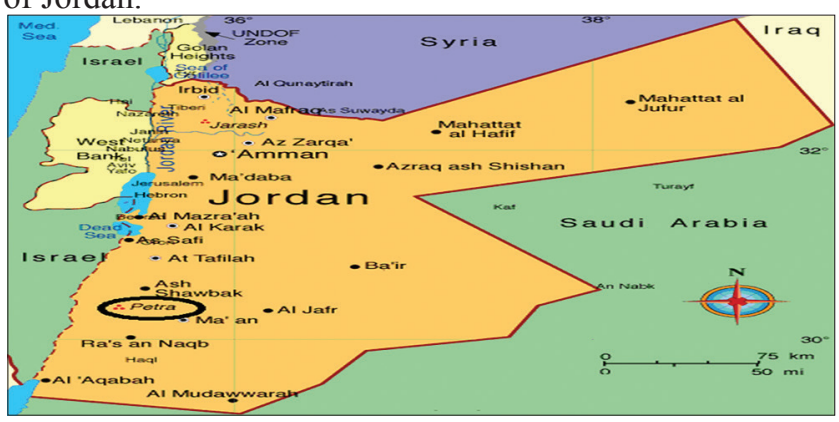

Figure 1. A map showing the countries bordering Jordan and the study location, Petra (Source: 1999 maps.com)

Socio-demographic data show that the current population of Jordan is approximately 9 million. $98 \%$ of the population are Arabs whilst about $2 \%$ are non-indigenous minority groups, including but not restricted to Circassians, Armenians, Chechens, and Kurds. Jordan is abundant in historical places, which have recently become popular destinations for foreign tourists, especially from Europe, the USA, Australia, and some countries in Africa and South America.

Returning to the map above, Petra is the most important historical place in southern Jordan. Petra is a dynamic touristic area having spectacular historical Nabataean ruins attracting foreign tourists from all over the world. Indeed, tourism industry has turned the city into a multilingual and multicultural urban centre. It has an important role in the social life of the local people, as is not only it a source of income for the town dwellers, but it is also highly valued among the residents as a symbol of national and supranational pride. Many historical sites in the city are internationally recognized, the most important of which is Al-khazneh (The Treasury).

It is no doubt that politeness and well-bred social behavior are essential pillars for building up communities, so much so that Islam emphasizes that the host should display courtesy and manners for the guest. The cultural values of hospitability and generosity are a demonstration of the duties of a good host in Jordan. As in many other Arab countries, people not showing domestic or non-domestic guests signs of respect, generosity, and hospitability would most likely bring shame and dishonor not only to the family but also to the country itself. Hatim al-Tayy, a well-known figure in the history of Arabs before Islam, who slaughtered all the camels of his father and even his own mare for his guests, was an inspiration for many Arabs, especially in Jordan (Shoup, 2007: 103).

The state of Jordan can be linguistically referred as a relatively monolingual rather than multilingual state. In the narrowest sense of diglossia, as suggested by Ferguson (1959), there is a divergence in usage where each language variety has a set of distinct functions. As far as Jordan is concerned, both Standard Arabic and Conversational Arabic are com- monly used in social settings and domains (The latter is primarily used in formal whilst the latter in informal domains.).

\section{English in Jordan: History and Contact}

The early signs of cultural Westernization could be traced back to Napoleon's occupation of Egypt (1781-1801), whilst the French, Italian, and British occupations of North Africa and the Arab Asian Middle East led to the spread of Western values in the Arab region. As other countries in the Arab Middle East, the state of Jordan came under Western colonial rule. During British colonial rule in Jordan, the son of Sharif Bin Al-Hussein was appointed as the prince of the Emirate of Jordan. After the Second World War, Jordan gained its independence in 1946. After the death of King Abdullah I, his eldest son Talal, who later left the throne for his son King Hussein in 1953, succeeded him.

Focusing on the history of English and its appeal as a global language was given impetus after Kachru's (1986) 'Concentric Circles'. According to the notion of World Englishes, a new English develops to serve the national interests of peoples and diverges from the standard linguistic forms (e.g. British and American English), which is apparent in the 'Outer Circle's' countries. Jordan is seen as a country with the 'Expanding Circle', which raises an important question of whether there exists a new English or it is just an imperfect competency in 'Native Englishes'. English is primarily being portrayed as the most significant language of worldwide intercultural communication. According to the notion of 'linguistic imperialism' as propelled by Phillipson (1992), it can be assumed that not only English but also the Western culture, especially the American and British cultures, is gradually globally spreading in new social settings with a view to the homogenization of other nations.

The history of English in Jordan has witnessed drastic changes since the British Mandate over Jordan in 1921. During the British Mandate, English was considered an official language for governance, education, and commerce in the West Bank of Jordan. In the East Bank of Jordan, English also had a significant presence as the language of the administration of the British authorities. As other colonial languages, English seemed to be associated with Western cultural and economic homogenization. Arabic has been lexically influenced by the influx of English lexical borrowings, a very important source of lexical innovations in Jordanian Arabic. In addition to code-switching, lexical borrowing was one of the early symptoms displaying signs of language contact between English and Jordanian Arabic (Jordanians have been heavily borrowing from the English language to express new concepts and items) (Alomoush, 2007; Alomoush \& Al Fagra, 2010; Alomoush \& Matarneh, 2010).

After independence in 1946, Arabic was constitutionally declared as the official language of the state. However, the teaching of English has been significantly developing since the foundation of the Hashemite kingdom of Jordan. The Arabic language is, on the one hand, the language of instruction in public and private schools at the primary and secondary levels. On the other hand, English is the only foreign language officially promoted and its functions are grad- 
ually extended at educational institutions, including but not limited to primary and secondary schools. The introduction of English into primary and secondary schooling has also been one of the state's most important deliberate language policies with a view to promoting the spread of the English language, which in turn helps undoubtedly to develop the country intellectually, economically, industrially, and technologically.

In the early 1920s, English was introduced into Jordanian schools and taught in a few urban centers: Al-Salt, Irbid, and Al-Karak. Teaching English was solely based on the grammar-translation model and no specific curricula and textbooks were used (Hamdan \& Abu Hatab, 2009:402). In the West Bank of Jordan, the British administration introduced English as a language of education in some secondary schools before 1947 (Harrison, 1975:19). After gaining independence in 1946, the educational system has been steadily developed. King Hussein who took the throne in 1952 and completed his school education at Harrow School in the UK played a major part in the teaching of English as a foreign language in private and public schools.

In the early 1980s, Ministry of Education modified the educational language policy in that English was taught from the fifth grade on in government schools because the need arises for new generations to be equipped with communicative skills in English. The instrumental value of English as a language adequate for science, industry, technology, and modernity has urged Jordan policy makers to support the gradual extension of the exposure of schoolchildren to the teaching of English from an early age. In 2001, Ministry of Education had a decision to introduce the teaching of English subject in the elementary school from the first grade instead of the fifth grade, which has had a significant effect on the competencies of schoolchildren in English.

To conclude, the current status of English can be partially explained by British colonialism. Other reasons include the reciprocal relationship between the spread of globalization and English, in addition to its usefulness as a global language, which guarantees the gradual extension of English in Jordanian social settings, especially institutional settings. In the age of globalization, there is an ongoing emphasis on the development of communication skills in English. It is currently utilized to have functions overlapping with those which are hypothetically linked to Standard Arabic in some domains, including educational and non-educational social settings. It would be more relevant to use English for the promotion of Jordan culture and customs instead of promoting the Western values.

\section{FIELDWORK METHODOLOGY}

According to a study conducted in the LL of Jordan (Alomoush, 2015), English constituted the second most visible language after Modern Standard Arabic, so anyone would presume that the LL would display a higher visibility of Arabic than English. Even though the language policy of the state of Jordan explicitly stipulates Arabic as the official language, English is implicitly promoted in public domains, as displayed on official signs. It would be feasible for the cate- gorization of the signs collected into monolingual, bilingual, and multilingual signs in order to evaluate the use of English in Jordan's touristic destinations.

Anyone walking into the commercial streets of Petra is struck by the pervasiveness of monolingual English signs. If you go to hotels, souvenir shops, food stores, restaurants, and all local shops, you will discover that English is the most dominant language on signs. It can be assumed that the sign inscribers are driven by a conscious and deliberate language policy adopting English as the lingua franca of the LL and highlighting the important role played by English as a promoter of tourism. Petra as a tourist destination is further considered an informal setting of learning, where the locals have different real opportunities to communicate with foreign tourists, including communication and interaction in shops and restaurants (Al-Naimat, 2006). Having noticed all these facts, the non-native use of English in the LL provides important sociolinguistic information on the Jordanian context.

Given that each LL is characterized by distinctive features, unique empirical research methods were employed to fully understand the role of English in historical places such as Petra, which was investigated in context as a symbolic space of history, culture, commerce, and tourism. The LL is not only a demonstration of the languages used in the community, but it might reflect globalized power structures in a predominantly Arabic-speaking country where international inbound tourism is primarily reflected through the extensive use of monolingual English signs.

With regard to the area where the study was carried out, commercial Petra includes two major streets: Central Petra Street and Tourist Street. The former, approximately five kilometers long, extends from Ain Mousa (The Spring of Moses), the starting borderline of Petra city, to the downtown. This street includes several hotels, shops of clothes and cell phones, pharmacies, bookshops, coffee shops, restaurants, tourist offices, bakeries, and supermarkets. The street, in particular the downtown, is considered a densely populated area, where the local and foreign people reside and go shopping. With regard to the LL data, Tourist Street, about nine Kilometers long, extending from the ending part of the city centre to Al Beyda, an area also known as 'little Petra' located a few Kilometers away from the ruins of Petra, constituted the study area. It includes a wide range of hotels, camps, coffee shops, restaurants, tourist offices, and supermarkets. For this reason, we selected a 900-metre stretch of the street on both sides in order to reflect more tourists' activities and practices. Being densely populated by foreign tourists is a characteristic that has marked this deliberately-selected area. Indeed, the area includes several luxurious hotels such as Mövenpick, Palace, Marriott, and Crowne Plaza, whose locations attract more tourists to stay nearby ancient Petra. Equally important, Petra Visitor Centre was established to help and provide visitors with all necessary information before starting their tours to Petra at the ancient main entrance.

The collection of data in Petra involved a two-staged approach. The first stage involved the mapping of the tourists' route, identifying the most frequent direction taken by tourists through Tourist Street, and observing the tourists' activities and practices over a period of five days. It was noted that a great number of tourists often took different means of 
transportation through Tourist Street, but they often reached the hotel area on foot (within the selected 900 meter-stretch of Tourist Street). The second phase was to take photographs of all static and non-static monolingual, bilingual, and multilingual signs by using a digital camera in the selected stretch of the above street. Even though the definition of 'sign' has not been settled in the field of LL, a sign was defined in line with Backhaus' (2007: 55) definition of LL data as: 'any piece of written text within a spatially definable frame', including shop signs, road signs, etc. Each sign was coded according to the language(s) used and the function displayed.

Ethnographic research methods were used to collect data through conducting interviews with foreign tourists and local shopkeepers together with the analysis of language policy texts. In this sense, folk linguistics can provide us with substantial insights on the interpretation of the visibility of particular languages in the LL. It is socio-linguistically sig- nificant to indicate how the participants would interpret the visual presence of the English language in a predominantly Arabic speaking environment. In what follows, we selected fourteen passers-by representing tourists from different countries of origin randomly, as displayed in Table 1:

The fieldwork also involved conducting informal interviews with 15 local residents in the city centre and the streets nearby Petra. Although there was no contiguous correlation between the interviewees' demographic backgrounds and their viewpoints regarding the predominance of English in Petra's LL, as Table 2 displays, the sample was designed to represent different Jordanian societal segments in terms of gender, age, education, and occupation in an endeavor to offer various perspectives into the current research project.

Most participants, as demonstrated in Table 2, were Jordanians whose ages fell into four subgroups: young people below 20 years, 20-39 years old people, middle-aged people (40-59),

Table 1. Demographic information on the foreign tourists participating in the interviews

\begin{tabular}{llllll}
\hline Participant No. & Nationality/origin & Gender & Age & Education & Occupation \\
\hline 1 & Asian & Female & 25 & High school & Bar manger \\
2 & United States & Female & 38 & College & Government \\
3 & United States & Female & 29 & Master degree & Teacher \\
4 & Senegal & Male & 50 & PhD & Medical doctor \\
5 & Chinese & Male & +60 & Bachelor degree & Manager \\
6 & Mexican & Male & 45 & Bachelor degree & Engineer \\
7 & Malaysian & Male & 30 & Bachelor degree & Teacher \\
8 & United States & Male & 66 & College & Retired pilot \\
9 & South Africa & Male & 56 & Diploma & Construction project manager \\
10 & Malaysia & Male & 33 & Bachelor degree & Consultant \\
11 & United states & Female & 26 & Master degree & Teacher \\
12 & United states & Male & 28 & High school/college & College student \\
13 & United kingdom & Female & 36 & Bachelor & Postgraduate student \\
14 & United states & Female & 30 & Bachelor's degree & Registered nurse \\
\hline
\end{tabular}

Table 2. Demographic information on the local participants in the interviews

\begin{tabular}{llllll}
\hline Participant No. & Nationality/origin & Gender & Age & Education & Occupation \\
\hline 1 & Jordanian & Male & 29 & Diploma & Shopkeeper \\
2 & Jordanian & Male & 57 & High school & Restaurant owner \\
3 & Jordanian & Male & 18 & High school & Bakery worker \\
4 & Jordanian & Male & 45 & Bachelor degree & Tourist office manager \\
5 & Jordanian & Male & 39 & Bachelor degree & Shopkeeper \\
6 & Jordanian & Male & +60 & Elementary school & Shop owner \\
7 & Jordanian & Male & 19 & High school & Sweet shop worker \\
8 & Jordanian & Male & 44 & College & Restaurant cashier \\
9 & Jordanian & Male & 51 & Diploma & Phone maintenance service \\
10 & Syrian & Male & 38 & Bachelor degree & Restaurant manager \\
11 & Syrian & Male & 20 & Secondary school & Restaurant waiter \\
12 & Egyptian & Male & 28 & High school & Shopkeeper \\
13 & Egyptian & Male & 23 & Secondary school & Shopkeeper \\
14 & Jordanian & Male & 21 & High school & Restaurant cashier \\
15 & Jordanian & Male & +60 & Bachelor degree & Tourist service office \\
\hline
\end{tabular}


and old-aged people (60 years and above). The participants' education levels and different occupations suggest their direct contact with foreign tourists in different local situations in Petra, such as bakeries, restaurants, shops, and tourist service offices.

\section{RESULTS AND DISCUSSION}

\section{English as a Substitute for Linguistic Diversity in The LL of Petra}

In order to show the linguistic diversity and the dominant use of English on both government and non-government signs in the town of Petra, we approached the LL through the existing languages. There were various languages such as Arabic, English, Japanese, Spanish, German, Russian, and Italian scattered throughout monolingual, bilingual, and multilingual signs in the town. Despite the fact that Arabic is the medium of public communication in the country, monolingual English signage was a key characteristic which had most marked the LL of Petra. Arabic-English bilingualism appeared on all government signs, but it was occasionally present on non-government signs ensuring that monolingual English practices prevailed.

The first major category included government-related signs made by Petra Development and Tourism Region Authority (PDTRA). There were a few municipal signs appearing in the LL: two road signs in Arabic and Romanized Arabic and one institutional sign in Arabic and English. Careful investigation of the remaining signs used in Petra's LL and the information provided on signs suggests considerable linguistic and social information about the country; apparently all the non-government signs were in full use with predominantly commercial functions associated with the industry of tourism, Jordan's cultural life, and even the long history of Jordan itself, as detailed below:

1. Promotion of touristic services: which provided foreign tourists with information about the tourist services not only in Petra but in other parts of Jordan such as Wadi Rum, Aqaba, and Wadi Araba. Names of Hotels were displayed in English. Examples included Edom Hotel, Mövenpick Hotel, Petra Guest House Hotel, and Crowne Plaza Resort. Some signs displayed different foreign languages such as Japanese, Russian, French, and German for the purposes of currency exchange.

2. The culture and customs of Jordan: particularly the Jordanian traditional cuisine such as Mansaf, Maqluba, Ghallaya, Koftah, Falafel, Hommos, Fatoush, Tabbullah, and Koba, all of which were only provided in Romanised Arabic. Other cultures were possible to be mentioned, as in the case of the following inscriptions: 'Pharaohs in Egypt', 'Turkish Baths', and 'Al-Andalusi Bazaar'. There were also translatable Arabic words transliterated in Roman characters such as Zaman (past), Hammam (bathroom), Zad (food), Al-Hayat (the life), Al-Andalusi, and Deretna (our home place).

3. Global branding: including brand names with English slogans e.g., Pepsi, Lipton, Nestle, Kodak Express, MasterCard, Visa, and Turkish Airlines.

4. Instruction and general information signs in English such as 'Open here', 'free', 'Push', and 'Petra Map'.
5. Announcements (e.g., discounts, special offers, etc.), most of which were present in English.

6. Other signs which included international movie stars such as Indiana Jones that was only provided in English and some political signs exclusively inscribed in Arabic.

In Table 3, monolingual signs were by far more numerous than multilingual signs. $72.4 \%$ of the signs were monolingual and $98 \%$ of all monolingual signs were in English, the characteristic that distinguished the LL of Petra from other Jordanian LLs. Compared to all the languages statistically appearing in Tables 3 and 4, English was widely spread in the LL. In the town of Petra, the English language occupies a variety of domains (e.g., private and public education, tourism, and commerce) and widely accepted throughout the town in the visual written marketplace, in addition to the fact that English is currently a lingua franca used by the local population to communicate with foreign tourists. On the basis of the above statistics, important conclusions can be made. The large number of monolingual signs can be explained in light of the tendencies of the sign producers to use English exclusively. The sign producers' linguistic choices reflect an overwhelming amount of language support and promotion for English as the most useful.

The LL results of the current study show that English is used as the lingua franca of Jordan's touristic LL. As discussed before, the reason why English has become the most prevalent code on monolingual signs (149 out of 152) in Petra is primarily associated with commercial and touristic functions. The type of signs used included shop signs (e.g., business name signs and other commercial information signs such as 'open' and 'closed' signs), advertisements, instructions such as 'Pull', 'Open', and 'Push', and brand name texts such as MasterCard, Visa, and Kodak. As displayed in Table 4, monolingual English signs appeared on approximately $98 \%$ of the total monolingual signs.

On commercial signs, English appeared alongside Arabic on twelve translated bilingual shop texts (e.g., business name signs in addition to business name signs with commercial information), and a bilingual hotel entrance sign 'Welcome to Petra', English also appeared alongside Romanized Arabic on six non-translatable bilingual food menus, including the traditional Jordanian cuisine such as 'Mansaf', 'Fatoush',

Table 3. Monolingual and multilingual signs in the LL of Petra

\begin{tabular}{lcc}
\hline Type of linguistic signs & Number & Proportion \\
\hline Monolingual signs & 152 & $72.4 \%$ \\
Bilingual signs & 55 & $26.2 \%$ \\
Multilingual signs & 3 & $1.4 \%$ \\
Total & 210 & $100 \%$ \\
\hline
\end{tabular}

Table 4. Languages on monolingual signs in Petra

\begin{tabular}{lcc}
\hline Languages present & Number & Proportion \\
\hline English & 149 & $98 \%$ \\
Arabic & 3 & $2 \%$ \\
Total & 152 & $100 \%$ \\
\hline
\end{tabular}


'Tabbouleh', 'Maklouba', 'Koftah', and 'Galayeh' and six translatable bilingual business name texts including words of Arabic origin such as 'Deretna' meaning 'our home place' and 'Zaman' meaning 'the past'. Undoubtedly, two different languages are currently standing out in Jordan, namely Arabic and English. That is why Arabic-English bilingualism is one of the most common advertising patterns in signage; in other words, the textual material is normally written in Arabic and English or at least one of them. In previous studies on the LL of Jordanian cities (e.g., Al-Naimat, 2015; Alomoush, 2015), the presence of both Arabic and English on signs has suggested that Jordanians are unable to live their lives without using the two languages. Indeed, the LL has placed an enormous amount of emphasis on the symbolic value of the Arabic language as a source of pride and national strength and that of English as a signifier of modernity and attraction, open-mindedness, and youth culture.

As Table 5 shows, English, Japanese, Spanish, French, German, Italian, and Russian were altogether found on two signs advertising foreign currency exchange services, and we noted that they were merely translated multilingual texts. The presence of these languages on a foreign currency exchange store was largely intended for foreign tourists in that they were seemingly authorized for providing information for a particular segment of tourist population (e.g., Native English-speaking people, Spanish, Russian, Japanese, French, Italian, and German) providing a remarkable regular source of income for business owners.

\section{The Role of English as a Lingua Franca in the Foreign Participants' Linguistic Repertoires}

The questions of the first part we asked were related to the language(s) used in private and public domains, particularly at home, in the workplace, and in the marketplace, outside and inside Jordan. The first question was intended for examining the language(s) used in speaking whilst the second question was related to the one(s) in reading and writing. The third and fourth questions examined the languages used in Jordan in relation to various domains of use.

The findings suggest a high vitality of English among the participants. With the overwhelming majority of the participants claiming for its being a central part of their linguistic repertoire, English was the most extensively used in speaking, reading, and writing. For many participants, English

Table 5. Languages on bilingual and multilingual Signs in Petra

\begin{tabular}{lcc}
\hline Languages present & Number & Proportion \\
\hline English + Arabic & 43 & \\
English + Romanized Arabic & 12 & $96 \%$ \\
English, + Japanese + Spanish & 2 & \\
+ French + German + Italian + & & \\
Russian & & \\
English + Arabacised English + & 1 & $4 \%$ \\
Arabic & & \\
Total & 58 & $100 \%$ \\
\hline
\end{tabular}

was the language habitually used in home, the marketplace, and the workplace. The ethnographic evidence elicited from the respondents shows that other languages are significantly less representative in their linguistic repertoire, including Spanish, Malay, Afrikaans, Chinese, Senegalese, French, and Arabic.

The subjects' responses emphasizes that the English language has become the global lingua franca in the present day's world. All the subjects used English either as a first language or as a second language. The majority of the participants used English as a first language in all daily life activities whilst a few participants used English in all domains of life as a second language, as other principal languages, particularly Spanish and French, were in a mode of competition with English as a second language in the linguistic repertoire of the participants.

With regard to the vitality of English in the domains of life in Jordan, all the participants agreed that English was the main medium of communication that they regularly used while other languages, particularly Arabic and French, were used by a few participants as a second language. This means that English as an international language puts great pressure on particular segments of the population (i.e., tourists belonging to various nationalities and ethnic backgrounds) to add English to the linguistic repertoire of the participants for social mobility and economic success.

\section{Foreign Participants' Attitudes towards English and Multilingualism in the LL of Petra}

The second part of the interview examined the perceptions and attitudes of the participants towards the position that the English language has in the LL of Petra and the reasons behind the current visual predominance. It was also intended for examining how important for the tourists to include more languages in the LL.

All the participants agreed that English was the most visually displayed language in Petra's LL. It seemed that most of the participants had a good command of the English language so many participants stressed the importance of English as the most widely spread language in the globe:

Interviewer: Do you think that English is the most visually displayed language in Petra's LL?

Interviewee (participant 8): Yes, off course.

Interviewer: Could you please tell us the reasons behind this dominance?

Interviewee (participant 8): We believe that English seems to be the common language beyond the visitors coming to Petra. Of course, we presumably speak English. I really had a wonderful experience!

The participant here linked the visual predominance of English to the mutual relationship between English and globalization. This means that the participants shared the view that English is currently the most used language on the planet by virtue of globalization and internationalization. Accordingly, it seems that the current expansion of English is somewhat related to economic ideologies (Pennycook, 2001). Its wide spread throughout the world means that it 
can function as a medium of international communication and its international promotion is evident in the economic benefits of English in globalization.

On the other hand, some participants thought that it was closely related to the fact that the local population understood English, which was present on more than half of the signs.

Interviewer: Do you think that English is the most visually displayed language in Petra's LL?

Interviewee (participant 2): Yes, of course!

Interviewer: Could you please tell us the reasons behind this dominance?

Interviewee (participant 2): All the vendors speak English to people passing.

It is interesting to note that shopkeepers communicated with tourists in English as reported by the participants. This might be explained in light of the fact that tourism constitutes an important source of income for shopkeepers whose livelihoods largely depend on inbound tourism. This supports what has been emphasized by Pennycook (2001); instead of acknowledging the popular perspective that the English language has become the current world's lingua franca of intercultural communication, he holds the belief that it still adheres to colonial discourses, and it cannot be entirely accepted that English is a neutral language without political and economic ideological constraints.

On the other side of the spectrum, some participants supported the addition of other international languages to the LL, even though the linguistic competence of Jordanians in principal languages such as French, Spanish, Italian, Russian, Japanese, and Chinese are extremely low as opposed to English. The competence in the above languages is associated with those who have educational, cultural and economic interests with France, Spain, Italy, Russia, Japan, and China, respectively. For example, participant 1 provided us with the languages that should appear in the LL with an explanation:

Interviewer: Do you that think that other languages should appear in Petra's LL?

Interviewee: Yes, it should be based on numbers from all the countries.

Interviewer: Can you tell us why please?

Interviewee: There are many tourists coming from Spain and France.

It is noteworthy that some participants thought that there was a lack of accommodation to the native language needs of many tourists, recommending a visibility of wider linguistic diversity in the marketplace based on the nationalities of tourists. The near-zero visibility of international principal languages was seemingly one of the key factors prompting the participants to do support a wider extent of multilingualism in the city. This can be attributed to the fact that Petra has recently become an international tourist destination. For the economy as a whole, inbound tourism is the key to the enjoyment of unprecedented prosperity and expansion of business and profitability in the town of Petra so that the addition of new languages to the LL plays a part in attracting more tourists coming from a wide spectrum of countries:

Interviewer: Do you that think that other languages should appear in Petra's LL?
Interviewee (participant 9): Yes, it should be based on numbers from all the countries. This should be done based on study as regards where visitors are from as this is where Petra is most likely being promoted as a tourist destination.

The participant acknowledged the symbolic value of other international languages, which explained the status of being visible in the LL, even though English played a significant role in the satisfaction of the language needs of all the participants. The above response indicated a great deal of motivation and interest among the participants towards multilingualism and multiculturalism in the LL. This perspective is in accordance with the current global trend to increase the degree of multilingualism and multiculturalism among societies where the knowledge of languages is a socio-economic asset and advantage that ultimately contribute to fostering and promoting intercultural communication and understanding. Nevertheless, the remaining participants did not share this view, arguing that they were no longer interested in the existence of foreign languages other than English, unquestionably the most reachable language in the era of globalization, which possibly poses threats to linguistic diversity and the knowledge of languages. This means that the economic advantages of English are historically unprecedented despite the belief that the continual of having economic benefits is ostensibly complicated (Grin, 2001). Reaching consensus on such a complex issue, English as a linguistic substitute for multilingualism, is never easy to settle down, but the current study indicates that English has a more visible role than other worldwide principal languages. Supporting an ideology of multilingualism symbolizes the promotion of the native language needs of a tourist population coming from different ethnic origins, whilst an English-only ideology reinforces the social cohesion of its members. The former ideology is apparently a superordinate consideration as English is the leading language in commerce and tourist industry even though multilingualism promotes worldwide economic competitiveness and intercultural communication.

\section{English In The Eyes of The Local Residents}

The analysis of the responses and viewpoints suggests that the interviewees' overall impression towards the greater use of English in Petra's LL was reciprocal in nature in the sense that the majority of people, in particular those working in the city centre at bakeries, mobile and sweet shops, and restaurants, was seemingly motivated by the mutual relation between English and globalization maximizing profits for small businesses and commercial companies, youth potential, and opportunities for the future in the local community. These views can be best represented by the following two excerpts:

Participant 4

I believe English is displayed here to address the global power of the language. Such a language is an essential part of every world city to portray how it is fashionable and prestigious. (Our Translation)

Participant 9:

Well, we use English on our shop signs to look different 
from the Arabic language as it is commonly used in Petra. I also see English as an attractive language for the young people today, which would ultimately motivate them to come into my store. (Our Translation)

The responses emphasizes the cosmetic beauty of English, as indexing a sense of change, youth, progress, fashion, prestige, and modernity (see Schlick, 2003). In other words, English was viewed as a signifier of global power and linguistic globalization making it an attractive language for the locals, and therefore, triggering more commercial activities. Even though English is thought of as being closely related to the supremacy of the Anglo-Saxon culture economically, technologically, and scientifically, it could be assumed that the respondents are entirely ignorant of the important role played by multilingualism in everyday life activities. Nor do they know whether multilingualism is an indication of a higher degree of cultural open-mindedness, tolerance, and refinement that contribute to the enhancement of commercial competitiveness and touristic industry. In the era of economic and cultural globalization in predominantly monolingual states where English is widely promoted, the function of using English on non-government signs is 'to persuade customers to buy the products or services available at the stores displaying these signs' (Edelman, 2009: 142). In France, for example, Lamarre (2014) has found out that English exists in some bilingual winks and bilingual wordplay in the LL of Montreal even though French has been supposed to be prevalent on all the signs.

Other responses, however, attributed the use of English for the reinforcement of more interaction and communication between the local residents and foreign tourist population: Participant 15

'Actually, I always use English on the signs of my storefront to allow the foreigners to read and understand the major reason behind engaging in business activities...I'm sure this'll make the tourists go shopping. (Our Translation)

On the one hand, the perceptions of the participants towards the use of English on signs is associated with the communicative function of English in the streets nearby Petra, which could be less understandable to the locals, and more accessible to the foreign tourist population. On the other hand, the wide spread of English on signs reveals a need for cultural and linguistic capital (Bourdieu, 1991, 1999), which can best explain why English is much more visible in the LL than other international languages in the sense that language does not only reflect economic issues but also economic facts. After all, is English not only believed to be communicative but also conceived as an instrument of power conveying a great deal of supremacy and economic prosperity.

\section{IMPLICATIONS AND CONCLUSIONS}

The findings reflect the two main goals of the research project (see the introductory part of the article for information). To attain these goals, both quantitative and qualitative methods were employed for gathering and analyzing data. This part is subdivided into non-theoretical implications of our findings and conclusions.

\section{Non-theoretical implications of our findings}

The LL normally reflects the languages used in a state or region, but it might be tactfully manipulated for linguistically satisfying the needs of tourists (Kallen, 2009), immigrants (e.g., Lou, 2009), or border populations (Martinez, 2004). The current study results confirm that the notable aspect of the data is the pervasiveness of monolingual English signs in the LL of Petra, which suggests that the social and economic ramifications of this omnipresence are enormous. Interestingly, Arabic is largely marginalized in the LL of Petra, even though Arab tourists outnumber foreign ones. This can be attributed to the communicative and symbolic values of the LL as a symbol of the relative power and status of the populations either permanently staying or sojourning (i.e., the residents and tourists). Nowadays, having a good knowledge of English is an advantage, so it can be assumed that the fact that English is much more visible than Arabic reflects socio-economic differences between the Western individuals and Jordanians. Foreign tourists normally stay relatively longer and consequently spend more money than Jordanian tourists do. If we only used the data collected in Petra regardless of the pervasive use of Arabic in other Jordanian linguistic landscapes (Alomoush, 2015), we would say that Arabic seems significantly stigmatized vis-a-vis the English language.

Although the current study might raise concerns about the predominance of English in an Arabic-speaking country, it is the first study that has attempted to examine the degree of English use in touristic Jordan in particular and in touristic Arab Middle East in general. The high frequency of English, as findings suggest, ultimately indicates that English is the most preferred language in the domain of tourism whose main concern is to target and reach the foreign tourist population. By comparison with a survey of the languages used in the LL of Jordanian cities (Alomoush, 2015), the high frequency of monolingual English signs in Petra ultimately contributes to better globalization for tourists. Using English advertising is one of the ways followed by shopkeepers to attract the attention of the tourists and display signs of Jordanian linguistic hospitability. The association of English advertising with Jordanian hospitability manifests itself in an environment where English language proficiency is stereotyped as an essential condition of being a good host.

In this investigation of signs in Petra, one of the world's most important places of cultural and historical heritage, it has been emphasized on the informational and symbolic functions of the extensive use of English in the LL. According to the results of our research, it is, apparently, now possible to infer that the touristic LL in Jordan is employed as an arena of language contact between Arabic and English through increasing the extent of multilingualism in a predominantly monolingual Arabic speaking country and encouraging more Jordanians to be multilingual in English as a second language. In the Jordanian context, the LL of Petra has revealed that English is present in two major forms: the standard form (American and British English) and the local linguistic form, which manifests itself through the creative use of the Roman script to advertise for traditional Jorda- 
nian cuisine. The newly 'globalized' language forms on commercial signs are combined by shopkeepers via mixing the Roman script with the local linguistic units (Jaworski \& Thurlow, 2010: 16). The local language in the Jordanian context has clearly manifested itself in the Roman script, as in the case of the word 'falafel' displayed in Figure 2.

Similarly, the transliteration of English into Arabic script can be ascribed to a new linguistic variety emerging from the mutual interaction between globalization and localization as maintained earlier (Gorter, 2006:88). Linguistic globalization is one of the characteristic features of English used on storefronts in the Jordanian LL (Al-Naimat, 2015; Alomoush, 2015). This linguistic technique provides scope for English to be widely spread among all segments of the Jordanian community. This is in compliance with the good-reasons hypothesis, as suggested by Ben-Rafael et al (2009: 16), which explains the use of English for its attractiveness to tourists and social prestige. Here in Figure 2, the restaurant uses English and Arabic in the Roman script in order to promote its services and foods for the touristic population.

In this investigation of signage in a historical area internationally known by history, archaeological ruins, and culture, we have extensively examined how English is used as the lingua franca of touristic Jordan, which means that the visibility of English in the Jordanian context is not only indexical of modernity and postmodern hybridity (Kallen \& Dhonnacha, 2010: 34). It can be suggested that advertisers (e.g., shopkeepers, companies and all potential agents) in this language community are undoubtedly fully aware of the existing and non-existing cultural and linguistic norms closely related to the linguistic repertoire of people and how the speech community views each code positively or negatively based on the social appropriateness of the words used according to domains of use and the potential instrumentality of each linguistic code. This in practice means that the Anglicization of the commercial streets of Petra is unsurprisingly a response to the linguistic needs of foreign tourists, irrespective of satisfying the visual language needs of Arab tourists. Whether as a consequence of attracting the foreign tourists or as an attempt of globalizing Petra as one of the world seven wonders, no one can ignore the fact that English has been dominating the touristic LL in Jordan.

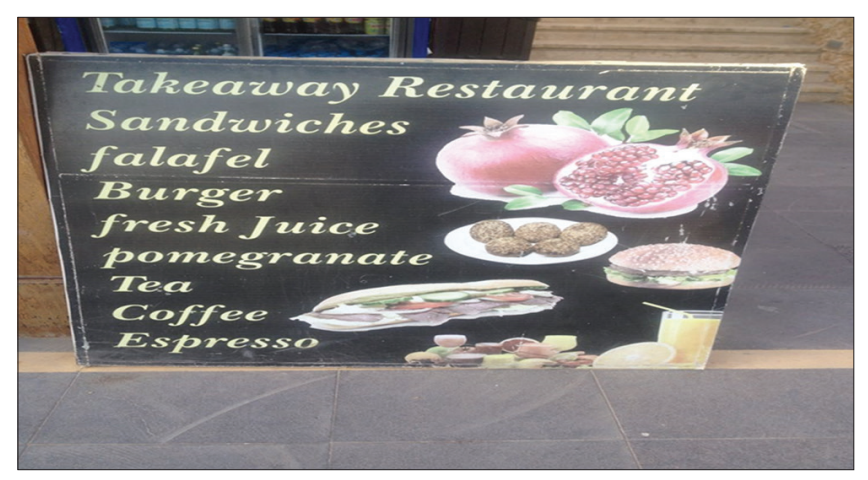

Figure 2. Non-translatable Romanized Arabic-English bilingual sign
Proper names appear to be an essential part of visual touristic Jordan; this is primarily evident in larger font sizes than other information displayed on signs. For example, the symbolic functions of English can be seen in the use of brand names such as 'Turkish Airlines', 'MasterCard', and 'Beck' exemplifying how worldwide commercial companies employ English to efficiently market and promote their products and services in the local tourist industry, manifesting themselves as semiotic, indexical, and mobilising signs in the public space (Al-Naimat, 2015). These observations are a further demonstration of the predominance of English in the domain of global branding in a tourism-dominated environment. In addition, the global value of English as a business naming language continues to rise (as reported in Alomoush, 2015). As Figure 3 illustrates, the introduction of English into business naming in Jordan is associated with the ideas of social prestige, modernity, and high quality, in addition to the belief that English-speaking nations, especially the USA and UK, are globally thought of as the leaders in the domain of technology, sciences, and fashion.

We may note, as Figure 4 illustrates, that English is more prominent than the Arabic lettering by virtue of a larger font size, amount of information provided, and the upper English lettering in complete capitals. The Arabic language could be argued to be of less important value vis-vi-vis to English.

The visibility of Western proper names as local store names outside Europe or English-speaking nations suggests different interpretations inside the Arab Middle East. More specifically, examples of Western names, as displayed in Figure 4, in a Jordanian context where European culture is stereotyped as a symbol of modernity, wealth, excellence, and cultural advancement are possible for foreign tourists to be thought of as a source of irony and humor, contextually as the space has not only a denotative but also connotative meaning.

Figure 4 displays the influence of the American culture on the language policies made by shopkeepers. Based on the responses elicited from the participants, we can infer that the global cosmetic value of English has brought a sense of unprecedented fondness and devotion to the Western, particularly American, life style. In the domains of commerce and tourism, the reciprocal relationship between globalization and English has been increasingly leading to reinforcing the

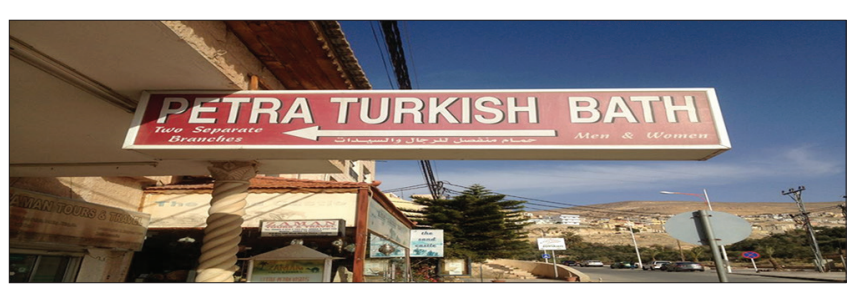

Figure 3. A translated English-Arabic bilingual sign

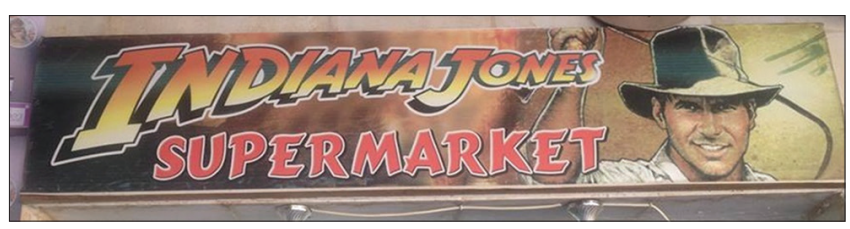

Figure 4. A monolingual English sign 
prestige of English and consequently diminishing the use of Arabic.

The attitude of the foreign tourist population towards multilingualism ranges from acceptance to rejection, which reveals that the assumption that English poses threats to linguistic diversity as a linguistic characteristic of the LL of Petra. However, it might be suggested that, according to the responses elicited from some of shopkeepers, English has a cosmetic rather than communicative value in order to attract the attention of both Arab and foreign tourists. Anyway, this cannot be taken for granted because English prevails in the local tourist industry as a code usually shared among members of the local and foreign tourist populations. Despite complaints from some participants for the absence of languages such as Spanish, French, Chinese, and so on, multilingualism is occasionally a characteristic feature of the LL of Petra, as shown in Figure 5.

Even though multilingualism might be beneficial for a society, it may be a source of societal anxiety, unrest, and dangerousness. Living in the middle of globalization, English would be the most commonly used language in all domains. In Figure 5, it seems that the English language remains the main language of communication with foreign tourists by virtue of a relatively larger font size in bold and top placement, even though the main wording in English 'Exchange' has been completely translated into six languages. The foreign currency exchange store does not overlook the relevance of other less prominent languages, as displayed in the exact order of Japanese, Spanish, French, German, Italian, and Russian together with the national flags of Japan, Spain, France, Germany, Italy, and Russia. In light of the current sociolinguistic research, it is no doubt that English is much more frequent than other languages, as it has increasingly become the lingua franca of the local tourist industry allowing different foreign populations to communicate with one another.

\section{CONCLUSIONS}

A number of tentative concluding remarks may be obtained from the current research LL study. The most remarkable feature that marked visual touristic Jordan in commercial Petra was that monolingual English signs dominated (a high frequency of English everywhere) whilst signs displaying Arabic were extremely low. With regard to the theoretical framework that has already been discussed in the first section of the article, the data gathered from both the LL of

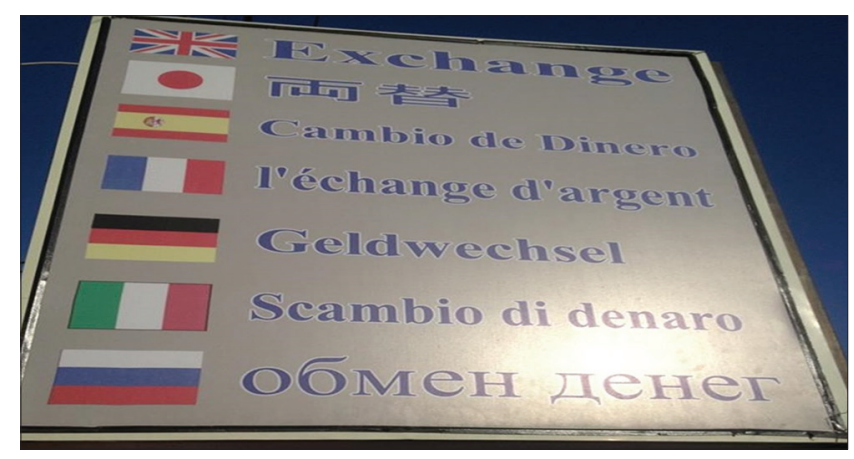

Figure 5. A translated multilingual sign
Petra and the foreign tourists suggest that economic factors have played an important role in the current proliferation of English in the city of Petra.

As a result of globalization and the symbolic role of English as the global language of tourism, commerce, and modernity, English was much more frequent than other languages, including Arabic. What is special about English in visual touristic Jordan is that it is not only used for communicative purposes, but it has great potential for being the globe's 'linguistic capital' (see Bourdieu, 1991, 1999, for a full discussion of the term 'linguistic market and capital' and others). Given the linguistic situation in Jordan, English has become deeply entrenched in educational and non-educational social settings and a successful substitute for greater linguistic diversity in the LL so that we would hardly expect that other principal languages (e.g. French, Chinese, Spanish, Japanese, and so on) to compete with English and Arabic in the foreseeable future, especially when we take into consideration that many members of foreign tourist and local resident populations have a fair working knowledge of English.

However, the dominance of English in the LL of Petra cannot only be accounted for communicative purposes and economic motivations. English seems to be positively valued and appreciated by foreign tourists and local residents. Even though the prevalence of English is historically associated with colonial ideologies and cultural homogenization, it has become a symbol of development, modern social norms, and open-mindedness. That is why other international principal languages no longer have the potential for competing with English in visual touristic Jordan, at least in the upcoming two or three decades.

\section{REFERENCES}

Al-Naimat, G. (2006) The interaction of secondary stage students with English speaking tourists in the Petra district. Unpublished MA thesis, Mu'tah University, Al-Kerak, Jordan.

Al-Naimat, G. (2015) Brand names in the linguistic Landscape of Aqaba, Jordan. PhD thesis, University of Liverpool, Liverpool, UK.

Alomoush, O. \& Al Fagara, W. (2010) 'The adaptation of English loanwords into Jordanian Arabic'. Journal of Language \& Literature, 2, 27-39.

Alomoush, O. \& Matarneh, M. (2010) 'The spread of code-switches into Jordanian social settings'. International Journal of Philosophy of Culture \& Axiology, 7 (20), PP.223-233.

Alomoush, O. (2007) Jordanian students' attitudes toward Anglicism: a sociolinguistic study. MA thesis. Yarmouk University.

Alomoush, O. (2015) Multilingualism in the linguistic landscape of urban Jordan. PhD thesis, University of Liverpool, Liverpool, UK.

Backhaus, P. (2007) Linguistic landscapes: A comparative study of urban multilingualism in Tokyo. Clevedon: Multilingual Matters. Barton, D. \& Hamilton, M. (1998) Local literacies: reading and writing in one community. London: Routledge. 
Ben-Rafael, E. (2009) 'A Sociological approach to the study of linguistic landscapes'. In E. Shohamy and D. Gorter (eds) Linguistic landscapes: Expanding the scenery. New York: Routledge.

Blackwood, R. \& Tufi, S. (2012) 'Policies vs. non-policies: Analysing regional languages and the national standard in the linguistic landscape of French and Italian Mediterranean cities'. In: Gorter, D. et al. eds. Minority languages in the linguistic landscape. Hampshire: Palgrave Macmillan, pp. 109-126.

Blommaert, J (2010) The sociolinguistics of globalization. Cambridge: Cambridge University Press.

Bolton, K. (2005) Where WE stand: approaches, issues, and debate in world Englishes. World Englishes, 24, 69-83.

Bolton, K. (2012) World Englishes and linguistic landscapes. World Englishes, 31(1), 30-33.

Bourdieu, P. (1991). Language and symbolic power. Cambridge: Polity Press.

Bourdieu, M. (1999) Economic Interaction of linguistics. Madrid: Akal

Cenoz, J. \& Gorter, D. (2006) 'Linguistic Landscape and Minority Languages'. In D. Gorter (ed.) Linguistic Landscape: A new approach to multilingualism. Clevedon: Multilingual Matters.

Coulmas, F. (1996) The Blackwell encyclopedia of writing systems. Oxford: Blackwell Publishers.

Crystal, D. (1997) English as a global language. Cambridge: Cambridge University Press.

Edelman, L. (2009) 'What's in a name? Classification of proper names by language. In: Shohamy, E. \& Gorter, D. eds Linguistic landscape: Expanding the scenery. New York and London: Routledge, pp. 141-154.

Fenyo, S.S. (2003). The Function of the English language in the European union. European Integration Studies, 2(2), pp. 53-64.

Ferguson, C. (1959) Diglossia. In: Giglioli, P. ed. Language and Social Context. Harmondsworth: Penguin Books, pp. 232-51.

Fishman, J (1977) Advances in the creation and revision of writing systems. The Hague: Mouton

Google maps. Available from URL http://maps.google.com (Accessed 5 September 2017).

Gorter, D. (2006) 'Further possibilities for linguistic landscape research', in D. Gorter (ed.), Linguistic landscape: A new approach to multilingualism, pp. 1-9. Clevedon: Multilingual Matters.

Grin, F. (2001) English as economic value: facts and fallacies. World Englishes, 20(1), pp. 65-78.

Hamdan, J.M \& Abu Hatab, W.A. (2009) 'English in the Jordanian Context'. World Englishes, 28 (3), pp. 394-405.

Harrison, W. et al. (1975) English-language policy survey of Jordan: A Case study in Language planning. Virginia: Centre for Applied Linguistics.

Jaworski, A, \& Thurlow, C. eds. (2010a) Semiotic landscapes: Language, image, space, London: Continuum.

Jaworski, A., \& Thurlow, C. (2010 b) 'Introducing semiotic landscapes'. In: Jaworski, A. \& Thurlow, C. eds., 'Semiotic landscapes: Language, Image, Space'. London: Continuum, pp. 1-40.
Kachru, B. B. \& Nelson, C. L. (2001) World Englishes. In: Burns, A. \& Coffin, C. eds. Analysing English in a global context. London: Routledge, pp. 9-25.

Kachru, B. B. (1986) The alchemy of English: the spread, functions and models of non-native Englishes. Oxford: Pergamon Press.

Kachru, B. B. (1992). Teaching world Englishes. In: Kachru, B. B. ed. The other tongue: English across cultures. Urbana: University of Illinois Press, pp. 355-365.

Kallen, J. (2009) 'Tourism and representation in the Irish linguistic landscape'. In E. Shohamy \& D. Gorter (eds) Linguistic landscape: Expanding the scenery. London: Routledge.

Kallen, J. (2010) 'Changing landscapes: Language, space and policy in the Dublin linguistic landscape'. In: Jaworski, A. \&Thurlow C. eds. Semiotic landscapes: language, image, space. London: Continuum, pp. 41-58.

Kallen, J. \& Dhonnacha, E. (2010) 'Language and inter-language in urban Irish and Japanese linguistic landscapes'. In Shohamy, E., Ben-Rafael, E. \& Barni, M. (eds.), Linguistic landscape in the city, 19-36. Bristol: Multilingual Matters.

Lamarre, P. (2014) Bilingual winks and bilingual wordplay in Montreal's linguistic landscape, International Journal of the Sociology of Language.

Landry, R. \& R. Y. Bourhis (1997) 'Linguistic landscape and ethnolinguistic vitality: An empirical study'. Journal of Language and Social Psychology, 16, 23-49.

Lou, J. (2009) Situating linguistic landscape in time and space: A multidimensional study of the discursive construction of Washington, DC Chinatown. Unpublished $\mathrm{PhD}$ dissertation, Georgetown University.

Martinez, G. A. (2004) 'Globalization, urban space, and the linguistic landscape along the Mexican-US border'. Geolinguistics, 30, 103-116.

Ministry of Tourism and Antiquities, The Hashemite kingdom of Jordan (2012). Available from http://www.mota. gov.jo/Documents/NTS_2011 2015_English.pdf (Accessed 27 December 2017).

Pennycook, A. (2001). 'English in the world/The world in English'. In: Burns, A. and C. Coffin (eds.) 2001) Analyzing English in a global context. London: Routledge, 78-89.

Pennycook, A. (2006) Global Englishes and Transcultural Flows. Routledge.

Pennycook, A. (2007) Global Englishes and transcultural flows. Abingdon: Routledge.

Phillipson, R. (1992) Linguistic imperialism. Oxford: Oxford University Press.

Phillipson, R. (2009). Linguistic imperialism continued. New York: Routledge.

Phillipson, R. (2015). 'English as threat or opportunity in European higher education'. In S. Dimova, A. K. Hultgren, \& C. Jensen (eds.), English-medium instruction in higher education in Europe (pp. 19-42). Berlin: Mouton de Gruyter.

Phillipson, R. (2016) 'Linguistic imperialism of and in the European Union'. In H. Behr \& J. Stivachtis (eds.), Revisiting the European Union as an empire (pp. 134-163). London: Routledge.

Pieterse, N. J. (2009) 'History and Hegemony: the United States and globalization', in B. Turner \& S. Bryan (eds.), 
The Routledge International Handbook of Globalization Studies, pp. 114-154. London: Routledge.

Reh, M. (2004) 'Multilingual writing: A reader-oriented typology -with examples from Lira municipality (Uganda)'. International Journal of the Sociology of Language, 170, pp. 1-41.

Rubdy, R. \& Saraceni, M. (2006). 'Introduction'. In R. Rubdy \& M. Saraceni (Eds.), English in the world: Global rules, global roles (5-16). London: Continuum.

Scollon, R. \& S. Scollon (2003) Discourses in places: Language in the material world. London: Routledge.

Schlick, M. (2003) 'The English of shop signs in Europe'. English Today, 19 (1), pp. 3-17.
Shoup, A. J. (2007) Culture and customs of Jordan. The United States of America: Greenwood Press.

Stavans, A \& Hoffman, C. (2015) Multilingualism. Cambridge: Cambridge University Press.

Svetlana, S. et al. (2015) The role of English in shaping the linguistic landscape of Paris, Berlin and Kazan. Social and Behavioral Sciences, 199, pp. 453 - 458.

Tufi, S., \& Blackwood, R. (2015).The Linguistic landscape of the Mediterranean: French and Italian coastal cities. Basingstoke: Palgrave Macmillan.

Yano, Y. (2001) World Englishes in 2000 and beyond. World Englishes, 20 (2):119-31. 